\title{
Getting to grips with sarcopenia: recent advances and practical management for the gastroenterologist
}

\author{
Thomas William Hollingworth (D) , ${ }^{1}$ Siddhartha M Oke, ${ }^{2}$ Harnish Patel, ${ }^{3}$ \\ Trevor R Smith ${ }^{1}$
}

${ }^{1}$ Department of

Gastroenterology, University Hospital Southampton NHS

Foundation Trust, Southampton, UK

${ }^{2}$ Department of

Gastroenterology, Saint Mark's Hospital, Harrow, UK

${ }^{3}$ Geriatrics, University Hospital Southampton NHS Foundation

Trust, Southampton, UK

\section{Correspondence to}

Dr Thomas William Hollingworth, Department of Gastroenterology, University Hospital Southampton NHS Foundation Trust, Southampton, Hampshire S016 6YD, UK; Thomas.Hollingworth@ UHS.nhs.uk

Received 13 October 2019 Revised 27 December 2019 Accepted 30 December 2019 Published Online First

20 January 2020

\section{Check for updates}

(c) Author(s) (or their employer(s)) 2021. No commercial re-use. See rights and permissions. Published by BMJ.

To cite: Hollingworth TW, Oke SM, Patel H, et al. Frontline Gastroenterology 2021;12:53-61.

\section{ABSTRACT}

Sarcopenia is a progressive and generalised disorder of skeletal muscle strength, function and mass, that is most commonly associated with the normal ageing process. It is increasingly recognised that sarcopenia can also develop as a consequence of malabsorptive and inflammatory conditions, such as those seen by gastroenterologists and hepatologists. It affects $1 \%-30 \%$ of the general population, but is seen in approximately $40 \%$ of patients with gastrointestinal conditions including inflammatory bowel disease and cirrhosis. Within this group of patients, it is associated with increased complications and mortality. The pathogenesis of sarcopenia is multifactorial with several risk factors implicated in its development including undernutrition, physical inactivity and coexistent multimorbidity. The SARC-F questionnaire has been developed to screen for patients at risk of sarcopenia, however, this focuses on the functional consequences and will therefore not identify those patients who are early in the progression of sarcopenia. There are several different non-invasive techniques available to assess muscle quantity and quality including; grip strength, dual energy X-ray absorptiometry, CT which can be used together to diagnose sarcopenia. Assessment and correction of malnutrition, particularly protein intake, in those at risk of sarcopenia is important in preventing the development and progression of sarcopenia. There are no specific drugs that are available for the treatment of sarcopenia, however, resistance exercise programmes combined with nutritional interventions show promise. It is important that this common condition is screened for and recognised, with any contributing factors addressed to reduce the risk of its progression.

\section{Significance of this review}

- Sarcopenia is defined as the progressive and generalised disorder of skeletal muscle function and mass that is associated with a number of important health outcomes.

- It can affect $1 \%-30 \%$ of the general population; but affects approximately $40 \%$ of patients with gastrointestinal conditions including inflammatory bowel disease and cirrhosis.

- The SARC-F questionnaire can be used to identify those at risk of sarcopenia.

- Assessment and correction of malnutrition, particularly protein intake is important in preventing the development and progression of sarcopenia.

- Grip strength, dual energy X-ray absorptiometry, gait speed and CT measurement of muscle mass can be used together in its diagnosis.

- No specific drugs are available for its treatment, but resistance exercise programmes combined with nutritional supplementation have shown promise.

\section{INTRODUCTION}

The sixth age shifts

Into the lean and slipper'd pantaloon With spectacles on nose and pouch on side,

His youthful hose well sav'd, a world to wide,

For his shrunk shank

Shakespeare, As You Like It, Act II, Scene VII, lines $157-161^{1}$

Skeletal muscle is an extraordinary, plastic tissue critical not only for locomotion and thermoregulation but also for metabolic homoeostasis, accounting for approximately $40 \%$ of total body mass. ${ }^{2}$ The association between the ageing process 


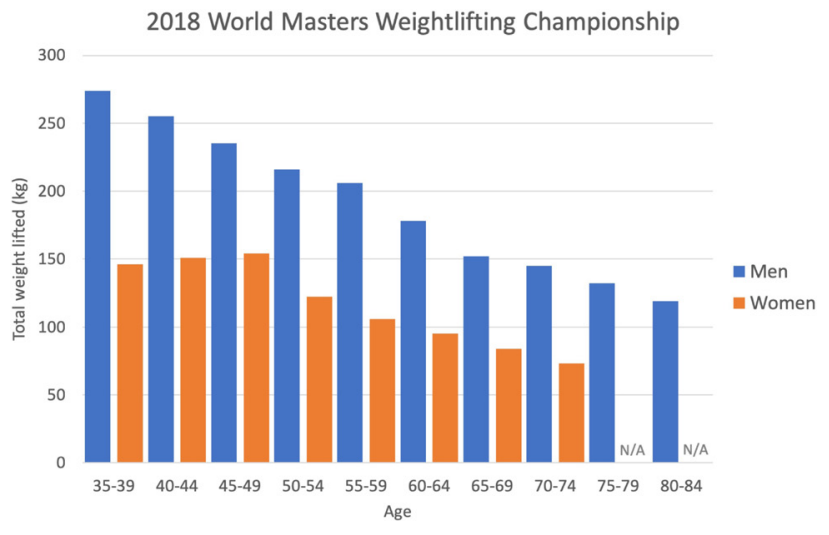

Figure 1 Results from the International Weightlifting Federation World Masters Championship 2018.

and muscle loss was first recognised by Critchley in 1931; noting a decline of lean body mass, with early signs being most noticeable in the intrinsic muscles of the hands and feet. ${ }^{3}$ The term sarcopenia, derived from the Greek words Sarx and penia, translated as poverty of flesh, was first used to describe this condition by Rosenberg in 1989, recognising that 'there may be no single feature of age related decline more striking than the decline in lean body mass in affecting ambulation, ability, energy intake and status, independence and breathing'. ${ }^{4}$ Sarcopenia is now widely recognised as muscle failure consequent to loss of skeletal muscle strength, function and mass.

While primary sarcopenia is considered part of the normal ageing process, nicely illustrated by the decline in the total weight lifted at the masters weightlifting championships with increasing age (figure 1), secondary sarcopenia has been described in conditions that are not solely a consequence of the ageing process, such as malabsorptive conditions, immobility/bed rest, starvation, hypothyroidism and a number of inflammatory conditions, that may be encountered in clinical practice 5 (figure 2). There is also recognition that sarcopenia can be an acute phenomenon, lasting less than 6 months, associated with an acute illness or injury. Both primary and secondary sarcopenia are associated with a broad range of adverse outcomes such as functional decline, falls, fractures, hospitalisation and increased hospital length of stay. ${ }^{6}$ A recent meta-analysis which included community dwelling, nursing home and hospitalised patients over the age of 60 , suggested a higher mortality OR (3.60) in individuals with sarcopenia; with those over 79 being at greatest risk. ${ }^{6}$ Furthermore, this systematic review and meta-analysis showed that the rate of functional decline, rate of falls and hospital admissions was higher in those who were sarcopenic. Sarcopenia is also associated with high personal, social and economic burden when left unrecognised and untreated, including disability, loss of independence and poor quality of life. Sarcopenia therefore represents a major health problem for men and women across all medical and surgical specialties especially in context of global demographic changes.

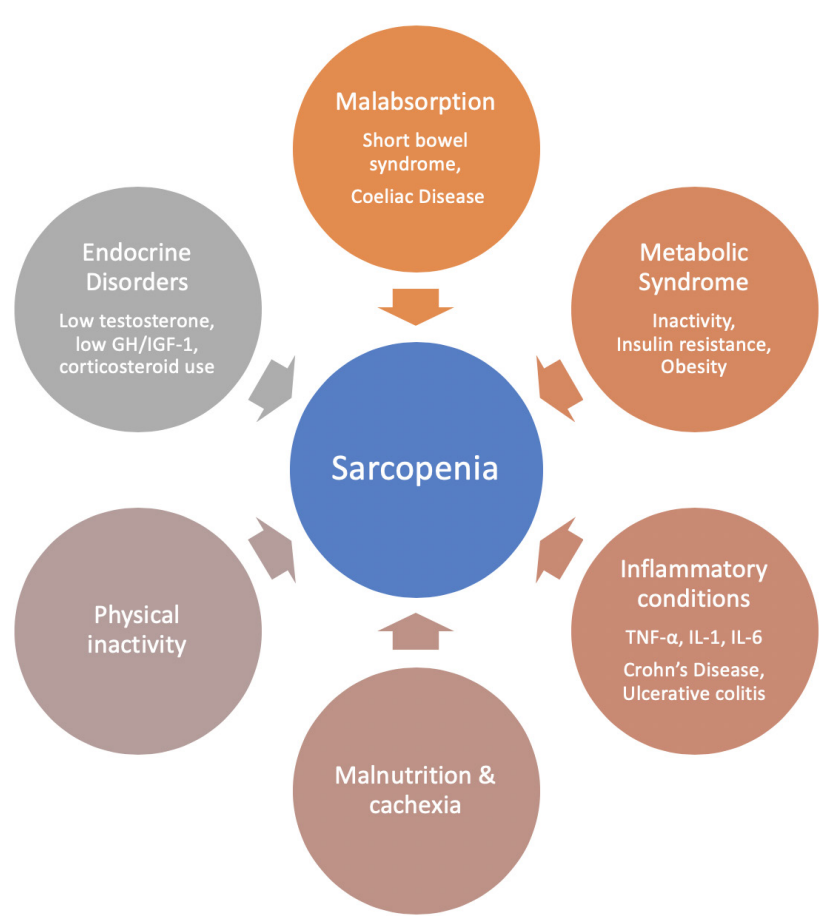

Figure 2 Contributors to sarcopenia relevant to clinical gastroenterology. GH, growth hormone; IGF-1, insulin-like growth factor-1; IL, interleukin; TNF- $\alpha$, tumour necrosis factor- $\alpha$.

In gastroenterology and hepatology patients, the development of sarcopenia is associated with; undernutrition, inflammatory bowel disease (IBD), ${ }^{78}$ liver disease $^{9}$ and intestinal failure (IF) ${ }^{10}$ It is associated with increased complications ${ }^{9}{ }^{11-14}$ and increased mortality. ${ }^{15}$ By proactively diagnosing and treating sarcopenia the clinical course for these patients can be significantly improved.

\section{DEFINING SARCOPENIA}

There are no universally accepted diagnostic criteria for sarcopenia. Consensus definitions have been produced by the European Working Group on Sarcopenia in Older People 2 (EWGSOP2), ${ }^{16}$ the International Working Group on Sarcopenia ${ }^{17}$ and the Asian Working Group for Sarcopenia ${ }^{18}$ which all include the measurement of muscle strength, muscle mass and physical performance, for example, through hand grip strength measurement, appendicular lean mass index (ALMi) and gait speed measurement ${ }^{1618}$ (table 1). The consensus definition produced by the EWGSOP2 was updated in 2018 using these measures ${ }^{16}$ (figure 3). The Foundation for the National Institutes of Health consortium has used regression tree analysis in pooled data from several studies, concluding that a combination of grip strength and ALM adjusted for body mass index (BMI) were the most reliable way of demonstrating the presence or absence of sarcopenia. ${ }^{19}$ An operational definition is needed to allow development and evaluation of interventions for prevention and treatment, and with the emergence of a number of candidate therapies, this has become more pressing. ${ }^{7}$ 
Table 1 Definition of sarcopenia by different groups

\begin{tabular}{|c|c|c|}
\hline Society & Definition & Cut-off point \\
\hline \multirow{5}{*}{$\begin{array}{l}\text { European Working } \\
\text { Group on Sarcopenia } \\
\text { in Older People } 2^{16}\end{array}$} & $\begin{array}{l}\text { Low ASMI adjusted } \\
\text { for height }\end{array}$ & $\begin{array}{l}\text { Men } \leq 7.0 \mathrm{~kg} / \mathrm{m}^{2} \\
\text { Women } \leq 6.0 \mathrm{~kg} / \mathrm{m}^{2}\end{array}$ \\
\hline & And either & \\
\hline & Gait speed & $<0.8 \mathrm{~m} / \mathrm{s}$ \\
\hline & $\mathrm{OR}$ & \\
\hline & Grip strength & $\begin{array}{l}\text { Men }<27 \mathrm{~kg} \\
\text { Women }<16 \mathrm{~kg}\end{array}$ \\
\hline \multirow[t]{3}{*}{$\begin{array}{l}\text { International Working } \\
\text { Group on Sarcopenia }{ }^{17}\end{array}$} & $\begin{array}{l}\text { Low ASMI adjusted } \\
\text { for height }\end{array}$ & $\begin{array}{l}\text { Men } \leq 7.23 \mathrm{~kg} / \mathrm{m}^{2} \\
\text { Women } \leq 5.67 \mathrm{~kg} / \mathrm{m}^{2}\end{array}$ \\
\hline & And & \\
\hline & Gait speed & $<1 \mathrm{~m} / \mathrm{s}$ \\
\hline \multirow[t]{5}{*}{$\begin{array}{l}\text { Asian Working Group } \\
\text { for Sarcopenia }{ }^{18}\end{array}$} & $\begin{array}{l}\text { Low ASMI adjusted } \\
\text { for height }\end{array}$ & $\begin{array}{l}\text { Men }<7.0 \mathrm{~kg} / \mathrm{m}^{2} \\
\text { Women }<5.4 \mathrm{~kg} / \mathrm{m}^{2}\end{array}$ \\
\hline & And either & \\
\hline & Gait speed & $\begin{array}{l}\text { Men } \leq 0.8 \mathrm{~m} / \mathrm{s} \\
\text { Women } \leq 0.8 \mathrm{~m} / \mathrm{s}\end{array}$ \\
\hline & $\mathrm{OR}$ & \\
\hline & Grip strength & $\begin{array}{l}\text { Men }<20 \mathrm{~kg} \\
\text { Women }<18 \mathrm{~kg}\end{array}$ \\
\hline
\end{tabular}

ASMI, appendicular skeletal muscle index.

\section{EPIDEMIOLOGY}

The prevalence of sarcopenia in the population varies widely in the published literature. This is likely to be a result of a heterogenicity of the criteria used for the diagnosis of sarcopenia including; different modalities for assessing muscle mass and function as well as different populations studied. In people over the age

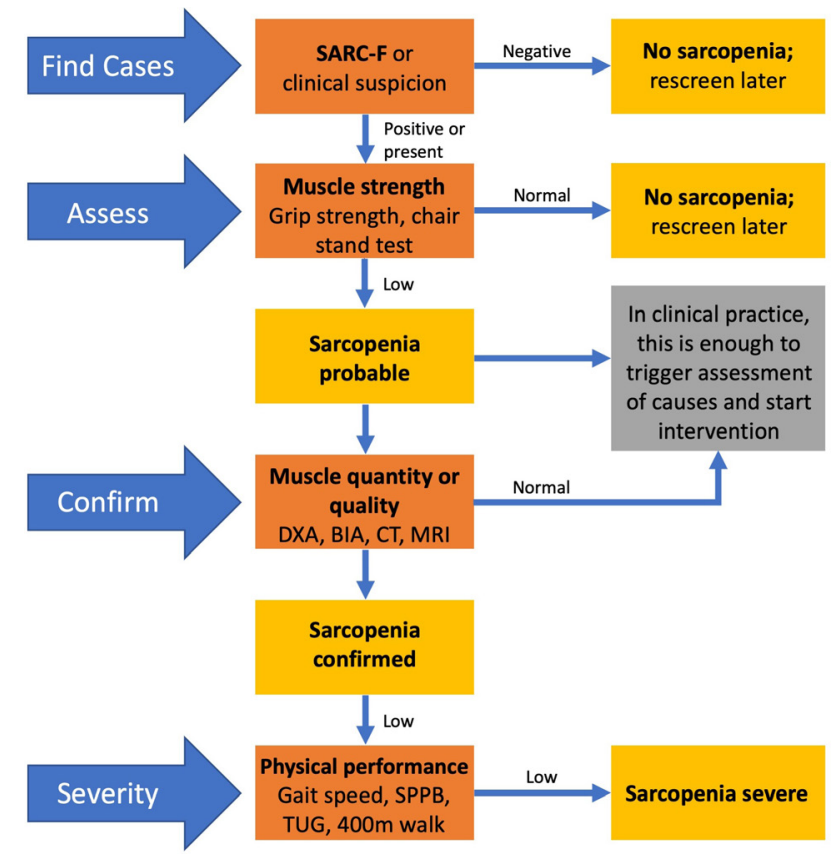

Figure 3 European Working Group of Sarcopenia in Older People updated algorithm for screening, diagnosis and assessing the severity of sarcopenia. BIA, bio-impedance; DXA, dual energy X-ray absorptiometry; SPPB, short physical performance battery; TUG, timed up \& go. of 60 , the reported prevalence ranges between $1 \%$ and $30 \%{ }^{20}$ The prevalence increases with advancing age, one study reported that $7 \%-10 \%$ of people aged between 60 and 70 years were sarcopenic while 30\% of those over 80 years of age were sarcopenic. ${ }^{17}$

\section{SARCOPENIC OBESITY, CACHEXIA AND FRAILTY: CLINICALLY DISTINCT BUT OVERLAPPING CONDITIONS}

Sarcopenic obesity is a separate condition characterised by reduced muscle mass in the context of increased adiposity. In addition to reduced muscle mass, excess adiposity also has a detrimental effect on muscle function and quality as a result of increased infiltration of fat into the muscle itself. ${ }^{16}$ Sarcopenic obesity is associated with disability, gait problems and falls to a greater extent than persons with 'proportionate' sarcopenia. ${ }^{17}$ In conditions such as malignancy, rheumatoid arthritis and ageing, lean body mass is lost while fat mass may be preserved or even increased. ${ }^{21}$ Fat is considered proinflammatory ${ }^{22}$ so may drive muscle catabolism in his regard.

Cachexia is a multifactorial condition characterised by severe body weight, fat and muscle loss. It occurs as a consequence of underlying illness, primarily driven by a marked inflammatory response. ${ }^{23}$ While the loss of muscle mass is also a feature of cachexia, most sarcopenic patients are not always cachectic. ${ }^{5}$ Frailty is a common clinical syndrome in which multiple body systems lose their reserves which can lead to weakness and poor functional capacity. ${ }^{24}$ Frailty is a state of physiological vulnerability driven by disruption of homoeostatic mechanisms in one or more systems for example, neurological, brain, endocrine as well as skeletal muscle as well as the occurrence of adverse events in the social and psychological domains that comprise the frailty syndrome. Sarcopenia is a core component of physical frailty domain and was well described in the seminal paper by Fried et al. ${ }^{25}$

\section{PATHOPHYSIOLOGY}

The pathogenesis of sarcopenia is multifactorial with several risk factors implicated in its development including undernutrition, physical inactivity and coexistent multimorbidity. Early fetal development also has important roles in the development of sarcopenia, with several birth cohort studies reporting a strong association between low birth weight and low hand grip strength and peak muscle mass. ${ }^{26-28}$ Cell and molecular consequences include an imbalance in muscle protein turnover, chronic inflammation, oxidative stress/mitochondrial dysfunction. ${ }^{29}$

Muscle mass is a function of muscle fibre (myofibre) number and cross sectional area. ${ }^{30}$ Cross-sectional and longitudinal studies have shown that muscle mass starts to decline in the fourth decade and progresses at a rate of $0.5 \%-1 \%$ a year with a more precipitous drop after the eighth decade. ${ }^{31}$ Muscle force is also impaired in parallel but not in direct proportion to 


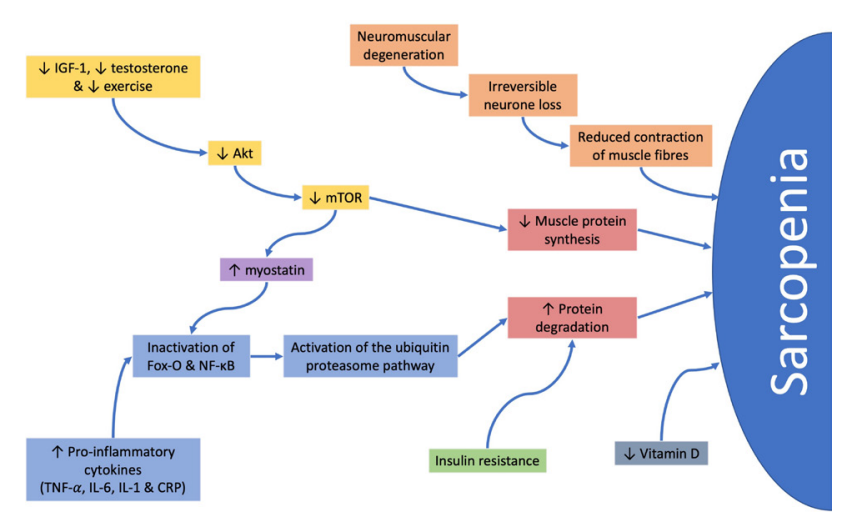

Figure 4 The different pathways implicated in the pathogenesis of sarcopenia. Akt, serine/threonine kinase; CRP, C-reactive protein; Fox-0, forkhead box-0; IGF-1, insulin-like growth factor-1; IL, interleukin; mTOR, mammalian target of rapamycin; NF- $\kappa B$, nuclear factor-kappa B.

the loss of muscle mass. The age-related loss of human skeletal muscle mass occurs through atrophy and loss of both myofibre type with greater preponderance in type II fibres; leading, through an imbalance of muscle protein synthesis and breakdown, fatty deposition and infiltration of non-contractile proteins, to a decreased muscle quality and function. ${ }^{31}$

The most completely understood pathway for muscle turnover involves activation of serine/threonine kinase which amplifies mammalian target of rapamycin leading to increased muscle protein synthesis. This pathway is upregulated by anabolic stimuli such as insulin-like growth factor-1 (IGF-1), testosterone and exercise. ${ }^{32}$ Testosterone is also implicated in the repair of myocytes through stimulation of myoblasts and inhibition of myostatin. Reductions in the levels of testosterone, IGF-1 and exercise occur with increasing age and lead to a downregulation of these pathways, ${ }^{33}$ causing a decrease in muscle protein synthesis and an increase in muscle breakdown.

Muscle breakdown can be further accelerated by insulin resistance, ${ }^{33}$ raised proinflammatory cytokines, ${ }^{34}$ genetic factors ${ }^{17}$ and poor nutritional status; including poor energy and protein intake leading to weight loss and low vitamin D status. ${ }^{35}$

Furthermore, in chronic inflammatory conditions, such as IBD, acute phase proteins and cytokines can have a direct effect on muscle degradation and myoblast apoptosis ${ }^{34}$ (figure 4).

\section{Challenges for practice in clinical gastroenterology}

Undernutrition, one of the main risk factors for the development of sarcopenia, affects over 3 million people in the UK, with $43 \%$ being over the age of $65.25 \%-34 \%$ of patients admitted to hospital are at risk of undernutri$\operatorname{tion}^{36}$ and it is recognised as a common complication of both IBD and liver disease. Studies estimate that undernutrition affects $65 \%-75 \%$ of patients with Crohn's disease, $18 \%-62 \%$ of patients with ulcerative colitis ${ }^{8}$ and $50 \%-90 \%$ of patients with cirrhosis. ${ }^{9}$

A 2017 systematic review reported that $41.6 \%$ of patients with IBD had sarcopenia. ${ }^{7}$ Interestingly, one study noted that $40 \%$ of sarcopenic patients with IBD had a normal BMI, with $20 \%$ overweight or obese. Studies have tried to identify risk factors for the development of sarcopenia in IBD which include BMI, ALMi measured by dual energy X-ray absorptiometry (DXA), $\mathrm{C}$-reactive protein, disease duration and body fat percentage. ${ }^{34}$ Three studies have been performed to look at the association between sarcopenia in IBD and the risk of requiring surgery and surgical outcomes. These studies have reported that sarcopenic IBD patients have a higher risk of requiring surgery, particularly colectomy when compared with the non-sarcopenic IBD population. ${ }^{12} 1337$ In one study, this effect was most pronounced in the obese, sarcopenic IBD patients. ${ }^{38}$ Two studies have shown a positive association between sarcopenia in the IBD patient and the prevalence of postoperative complications. $^{37} 39$ In subgroup analysis it was found to be significantly associated with postoperative sepsis, increased length of hospital stay, deep vein thrombosis and admission to the intensive care unit. ${ }^{39}$

There is little published research on the incidence of sarcopenia in liver disease, with two studies reporting it being present in approximately $40 \%$ of patients. ${ }^{9}$ Prospective studies have shown that undernutrition and sarcopenia are independent risk factors for variceal bleeding and mortality in these patients. ${ }^{14}$ The median survival for patients assessed for liver transplantation in one centre was reported as 34 months in non-sarcopenic patients compared with 19 months in sarcopenic patients. This was as a consequence of a significantly higher incidence of sepsis related deaths in the sarcopenic group. ${ }^{15}$ Furthermore, skeletal muscle plays a significant role in ammonia detoxification placing sarcopenic, cirrhotic patients at a higher risk of developing hepatic encephalopathy. ${ }^{9}$

Sarcopenia is an increasingly recognised phenomena in patients with IF. To date, data on prevalence are limited, with the largest recent study demonstrating a prevalence of $72.7 \%$ in patients with IF. ${ }^{10}$

\section{SCREENING}

The EWGSOP2 recommend screening for sarcopenia prior to measuring muscle strength (figure 2). The SARC-F questionnaire has been developed to identify those at risk of sarcopenia by assessing their functional capacity in everyday activities. ${ }^{40} 41$ This simple questionnaire assesses the difficulties a patient has in performing everyday tasks including; carrying heavy loads, walking, transferring from chair to bed, climbing stairs as well as the number of falls in the past year, with a score of 0,1 or 2 assigned to each category. A score of $\geq 4$ suggests evidence of symptomatic sarcopenia (table 2). 
Table 2 SARC-F screen for sarcopenia

\begin{tabular}{|c|c|c|}
\hline Component & Question & Scoring \\
\hline Strength & $\begin{array}{l}\text { How much difficulty do } \\
\text { you have in lifting and } \\
\text { carrying } 10 \text { pounds? }\end{array}$ & $\begin{array}{l}\text { None }=0 \\
\text { Some }=1 \\
\text { A lot or unable }=2\end{array}$ \\
\hline $\begin{array}{l}\text { Assistance in } \\
\text { walking }\end{array}$ & $\begin{array}{l}\text { How much difficulty do } \\
\text { you have walking across } \\
\text { a room? }\end{array}$ & $\begin{array}{l}\text { None }=0 \\
\text { Some }=1 \\
\text { A lot, use aids or unable }=2\end{array}$ \\
\hline Rise from chair & $\begin{array}{l}\text { How much difficulty do } \\
\text { you have transferring } \\
\text { from a chair to a bed? }\end{array}$ & $\begin{array}{l}\text { None }=0 \\
\text { Some }=1 \\
\text { A lot or unable without } \\
\text { help }=2\end{array}$ \\
\hline Climb stairs & $\begin{array}{l}\text { How much difficulty do } \\
\text { you have climbing a } \\
\text { flight of ten stairs? }\end{array}$ & $\begin{array}{l}\text { None }=0 \\
\text { Some }=1 \\
\text { A lot or unable }=2\end{array}$ \\
\hline Falls & $\begin{array}{l}\text { How many times have } \\
\text { you fallen in the last } \\
\text { year? }\end{array}$ & $\begin{array}{l}\text { None }=0 \\
1-3 \text { falls }=1 \\
4 \text { or more falls }=2\end{array}$ \\
\hline
\end{tabular}

A score $\geq 4$ is considered to be evidence of symptomatic sarcopenia.

While SARC-F has been validated in several international cohorts of older patients ${ }^{40-42}$ with excellent specificity (98.1\%), it has poor sensitivity (29.5\%) for sarcopenia. ${ }^{43}$ Furthermore, this screening tool only identifies those who have functional consequences of sarcopenia and will therefore does not identify those patients who are early in the progression of sarcopenia or those who are able to compensate for their sarcopenia. Attempts have been made to simplify and refine SARC-F with a consequent reduction in sensitivity and specificity. ${ }^{43}$ An additional screening tool is available in the form of the Ishii screening test which estimates the probability of sarcopenia based on age, grip strength and calf circumference ${ }^{44}$ with studies showing a specificity of $84.3 \%-100 \%$ and sensitivity of $74.3 \%-80.9 \%$, depending on the definition of sarcopenia used. ${ }^{45}$

\section{ASSESSMENT OF SARCOPENIA}

The EWGSOP2 diagnostic algorithm recommends ascertainment of muscle strength followed by either intervention if sarcopenia is suspected or follow-up by measurement of muscle mass and physical performance (figure 3). There are many different tools available for the assessment of sarcopenia which assess muscle strength and quantity. In the past there has been a lack of gold-standard techniques for the diagnosis of sarcopenia due to a lack of agreement of the definition of sarcopenia and hard end points for intervention.

\section{Measuring muscle strength}

The measurement of grip strength is an inexpensive and simple tool available using a calibrated handheld dynamometer. ${ }^{46}$ Measurements of grip strength correlate well with the strength of other muscle compartments with good reliability and reproducibility. This ease, reliability and availability has led to its recommendation for use in both hospital and community settings ${ }^{47-49}$ (table 1). Surrogate assessments can also be used in those who are unable to use a dynamometer, such as the chair stand test. This measures the amount of time it takes a patient to rise from sitting five times as an assessment of the strength of proximal leg muscles.

\section{Measuring muscle mass and quantity}

There are several different non-invasive imaging techniques available to assess muscle quantity including appendicular skeletal muscle index (ASMI) via DXA, CT, MRI or ultrasound. ASMI measured by DXA is currently the most favoured modality for quantifying muscle quantity. ${ }^{50}$ DXA scanners emit X-ray photons at two energy levels, the ratio of the attenuation of these two energy levels allows for an estimation of soft tissue mass in relation to body size. From this further extrapolations can be made to calculate lean mass, fat mass and muscle mass and from there appendicular skeletal mass, ${ }^{51}$ which is used in the study of sarcopenia. The advantages of DXA are that it has low radiation doses, it is quick and non-invasive with reproducible results, when the same equipment is used. There are however differences in results between different DXA instrument brands and it is not portable, limiting use in the community.

CT and MRI have long been considered the gold standard for the non-invasive assessment of muscle quantity as well as quality in the entire body. This process can be time consuming and therefore a method of calculating of skeletal muscle mass using a CT image taken at the level of the third lumbar vertebra (L3) (LSMI) has been developed and validated. This measures the total muscle mass formed from the psoas, paraspinal muscles and abdominal wall, standardising the total surface area for height to form the L3 muscle index (total muscle surface area $\left(\mathrm{cm}^{2}\right) /$ height squared $\left(\mathrm{m}^{2}\right)$ ), providing an estimation of total skeletal body muscle. ${ }^{52}$ This method has the advantage of being very accurate, with reproducible results and can be taken from a CT or MRI taken for another purpose. It has been used to detect low muscle mass, predicting mortality in cancer patients ${ }^{53} 54$ or outcomes in the intensive care unit. ${ }^{55}$ It does, however, expose patients to ionising radiation limiting its use in sequential measurements to assess response to treatment. This is in addition to the high equipment costs, lack of portability and requirement for highly trained clinicians to assess the imaging. Muscle ultrasound is widely used within the research community for the assessment of both the quantity and quality of muscle by measuring muscle thickness, cross-sectional area, fascicle length, pennation angle and echogenicity. ${ }^{56}$

Bio-impedance (BIA) has long been used to estimate ASMI through the measurement of whole-body electrical conductivity. The principle behind BIA is that current is well conducted by water, blood and muscle and poorly by fat, air-filled spaces and bone. In order to estimate whole body composition, electrodes are placed in a tetrapolar arrangement on both hands and 
feet. The impedance is calculated by a vector calculation which takes into account the resistance and reactance of the current in combination with a phase angle (created from the capacitance of the tissue)..$^{57}$ BIA has advantages of being safe, inexpensive with portable equipment that is rapid to use. It does however have several problems, the first of which is that the readings obtained are algorithmic calculations based on assumptions of the standard body composition. In certain disease states where both composition and body geometry are altered the accuracy of this technique is therefore brought into question.

\section{INTERVENTIONS}

The EWGSOP2 algorithm recommends early intervention in all patients with suspected sarcopenia after the measurement of grip strength (figure 3). Studies have looked at several different interventions to improve muscle mass, quality and function in patients with sarcopenia; including exercise interventions to improve muscle strength and physical performance, nutritional supplementation to improve muscle protein synthesis and pharmacological agents to reduce muscle turnover.

\section{Nutritional interventions}

There is a significant decline in food and energy intake with increasing age and associated with many chronic diseases associated with sarcopenia. ${ }^{59}$ There have therefore been a significant number of studies assessing the effect of nutritional supplementation, particularly; protein, vitamin $\mathrm{D}$, amino acid, beta-hydroxy-betamethylbutyrate (HMB) and fatty acids on sarcopenia.

Dietary protein provides essential amino acids for the synthesis of muscle protein, in addition to providing an anabolic stimulus that increases muscle protein synthesis. The body is unable to store unused protein for periods of catabolic stress, such as hospitalisation or illness, instead relying on skeletal muscle as a reservoir. This is even more crucial in patients with malabsorptive or other gastroentrological problems that limit their nutrition intake. If adequate protein consumption is not maintained, skeletal muscle amino acids are released during these periods of stress leading to muscle atrophy, impaired muscle function and growth. ${ }^{60}$ (National Institute for Health and Care Excellence (NICE) guidelines suggest that well patients require $0.8-1.5 \mathrm{~g}$ of protein per kg per day. ${ }^{61}$ The PROT-AGE study has subsequently calculated that the optimal dietary intake of protein is between 1 and $1.2 \mathrm{~g}$ of protein per $\mathrm{kg}$ per day, ${ }^{62}$ with $1.2-1.5 \mathrm{~g} / \mathrm{kg} /$ day required, when combined with exercise to maintain function. It is important to recognise those patients who are unable to meet these requirements or are already malnourished, using screening tools such as a Malnutrition Universal Screening Tool (MUST) score. In these patients a dietetic assessment is important to assess and maximise their nutritional intake or provide nutritional support. Commonly simple interventions, such as the provision of oral nutritional supplements would provide $12 \mathrm{~g}$ of protein, $300 \mathrm{kcal}$, in addition to a full range of vitamins and minerals.

One study has been performed that has highlighted the benefits of adequate nutrition and protein supplementation in 114 sarcopenic IBD patients undergoing surgery for disease management. In this study, patients receiving preoperative enteral or parenteral nutrition had a significant reduction in major postoperative complications when compared with those that had not $(6.5 \%$ vs $28.6 \%) .{ }^{37}$ The effect of protein supplementation on muscle mass and functional capacity has been assessed in five studies, ${ }^{62-67}$ of these only one study did not include an exercise programme. While the remaining three studies supplemented participants normal diet with between 30 and $40 \mathrm{~g}$ of protein a day in divided doses over a period of 24 weeks to 18 months. All of these studies showed no improvement in muscle strength nor physical performance. There are no studies that assess the use of parenteral nutrition in the treatment of sarcopenia, however, a recent study has reported a significant improvement in LSMI, but not anthropometric measurements following the provision of parenteral nutrition. ${ }^{68}$

Vitamin D deficiency is commonly found in both sarcopenic patients and those with gastrointestinal disorders. Studies have reported a prevalence of $70 \%$ in Crohn's disease, $40 \%$ in ulcerative colitis (UC) ${ }^{8}$ and $64 \%-92 \%$ in cirrhosis. ${ }^{69}$ It has been postulated that vitamin $\mathrm{D}$ deficiency can accelerate sarcopenia with epidemiological evidence that normalisation of vitamin D levels can prevent falls indicating an improvement in functional capacity. ${ }^{70}$ No studies have been performed that look at vitamin D and sarcopenia.

Amino acid supplementation, in the form of leucine has been shown to increase muscle protein synthesis and has been used to improve athletic performance. ${ }^{71}$ There had, therefore, been hope that this may be helpful is sarcopenia when assessed in two high quality studies. ${ }^{72} 73$ In these studies participants ingested $6 \mathrm{~g}$ or $15 \mathrm{~g}$ of leucine in an enriched diet for a 3-month period. This intervention alone did not improve muscle strength or functional capacity, however when combined with an exercise programme there was an improvement in muscle mass and strength, but not functional capacity.

HMB supplementation has been studied in sarcopenia combined with lysine and arginine, ${ }^{74}$ with exercise $^{75}$ or on its own. ${ }^{7677}$ In these studies participants received 2-3 g of HMB a day for between 8 and 24 weeks. HMB improved muscle mass in one study of participants on extended bed rest ${ }^{76}$ and muscle strength ${ }^{74}$ when combined with lysine and arginine.

Eicosanoids, derived from unsaturated fatty acids, are considered one of the mediators and regulators of inflammation. It was therefore postulated that by changing the dietary intake of n-3 and n- 6 long chain fatty acids could have an impact on inflammatory driven sarcopenia. Sadly, in the one study performed 
using $\alpha$-linolenic acid a fatty acid supplement when combined with an exercise programme, no significant change was recorded in muscle mass or strength when compared with placebo. ${ }^{78}$

While the provision of oral or parenteral nutrition is vital and supported by national and international guidance in these patients, there are no consensus guidelines for nutritional supplementation in sarcopenia; this is an area of exciting future research.

\section{Exercise}

Resistance exercise, particularly progressive resistance exercise, has been shown to be the best current treatment available to improve muscle mass, strength and the functional capacity of older adults. ${ }^{79-81}$ Of five studies performed using resistance exercise alone, three reported an improvement in muscle mass and four reported an improvement in both muscle strength and the functional capacity of participants when compared with simple home exercises. ${ }^{79-83}$ These resistance training programmes have included free weights, weight machines, whole body vibration and elastic bands. ${ }^{84}$ This is supported by the 2009 Cochrane review which looked at 121 trials and concluded that resistance exercise resulted in improved muscle strength and function. ${ }^{83}$ Simple measures to increase physical activity have also been shown to decrease symptoms of frailty and improve muscle function. ${ }^{85}$ Although studies have shown a benefit of both exercise and resistance exercise, none have recruited participants based on their sarcopenic status, therefore the results cannot be directly translated to sarcopenia. ${ }^{20}$ Just being physical active may confer some beneficial effect on skeletal muscle health. A recent cross-sectional study of objectively measured physical activity in 32 men and 99 women suggested that all intensities of physical activity may be protective against sarcopenia. ${ }^{86}$

\section{Pharmacological interventions}

Pharmacological interventions for sarcopenia have focused on hormone replacement, particularly testosterone with conflicting results. An improvement in muscle mass can be achieved with testosterone replacement, however, this was not associated with an improvement functional capacity. ${ }^{87} 88$ Other treatments trialled include growth hormone supplementation which, while increasing muscle mass, was associated with an increase in adverse events. ${ }^{89}$ Ghrelin mimetics have been used to improve appetite and food intake which, in one study showed an improvement in stair climbing time and gait at 12 months. ${ }^{90}$ However, to date there are no drug treatments for sarcopenia although there is burgeoning research in this area paralleled by basic and molecular studies of skeletal muscle to identify key molecular pathways that can be targets for drug discovery.

\section{CONCLUSIONS}

Sarcopenia or muscle failure is an increasingly common condition that is associated with significant negative health outcomes. It is increasingly common in patients with gastrointestinal or liver disease, with significant clinical consequences. Sarcopenia is still poorly recognised by clinicians, in part due to the lack of a consensus definition. However, similar to malnutrition, it should become standard practice that we screen all patients for sarcopenia, using tools such as SARC-F screening tool, across a range of clinical settings. Furthermore, those identified as being at risk should be assessed by simple measures such as grip strength, which can be performed in the community or outpatient setting. Confirmation of sarcopenia can be achieved by measurement of ALM by DXA or alternatively use pre-existing abdominal imaging to calculate the L3 muscle index. Simple assessment and interventions, such as better recognition and malnutrition and nutritional supplementation can have a significant impact on the outcomes of patients. Physical activity is the cornerstone of sarcopenia management at present. Resistance exercise programmes combined with nutritional interventions show promise in the treatment of sarcopenia although more trials in sarcopenia are needed to provide a clear programme of treatment.

Twitter Thomas William Hollingworth@motilitydoc

Contributors TWH performed a literature search and wrote the article. SO contributed to the writing of this article. TRS and HP reviewed and edited the article.

Funding The authors have not declared a specific grant for this research from any funding agency in the public, commercial or not-for-profit sectors.

Competing interests None declared.

Patient consent for publication Not required.

Provenance and peer review Commissioned; externally peer reviewed.

\section{ORCID iD}

Thomas William Hollingworth http://orcid.org/0000-00033134-6648

\section{REFERENCES}

1 Shakespeare W. As you like it, 1623.

2 Sender R, Shai Fuchs RM. Revised estimates for the number of human and bacteria cells in the body RON. PLOS Biol 2013;14:1-21.

3 Critchley M. The neurology of old age. The Lancet 1931;217:1119-27.

4 Rosenberg IH. Summary comments. Am J Clin Nutr 1989;50:1231-3.

5 Muscaritoli M, Anker SD, Argilés J, et al. Consensus definition of sarcopenia, cachexia and pre-cachexia: joint document elaborated by Special Interest Groups (SIG) "cachexia-anorexia in chronic wasting diseases" and "nutrition in geriatrics". Clin Nutr 2010;29:154-9.

6 Beaudart C, Zaaria M, Pasleau F, et al. Health outcomes of sarcopenia: a systematic review and meta-analysis. PLoS One 2017;12:e0169548.

7 Ryan E, McNicholas D, Creavin B, et al. Sarcopenia and inflammatory bowel disease: a systematic review. Inflamm Bowel Dis 2019;25:67-73. 
8 Scaldaferri F, Pizzoferrato M, Lopetuso LR, et al. Nutrition and IBD: malnutrition and/or sarcopenia? A practical guide. Gastroenterol Res Pract 2017;2017:1-11.

9 Montano-Loza AJ. Clinical relevance of sarcopenia in patients with cirrhosis. World J Gastroenterol 2014;20:8061-71.

10 Skallerup A, Nygaard L, Olesen SS, et al. The prevalence of sarcopenia is markedly increased in patients with intestinal failure and associates with several risk factors. Clin Nutr 2018;37:2029-35.

11 Zhang T, Cao L, Cao T, et al. Prevalence of sarcopenia and its impact on postoperative outcome in patients with Crohn's disease undergoing bowel resection. JPEN J Parenter Enteral Nutr 2017;41:592-600.

12 Zhang T, Ding C, Xie T, et al. Skeletal muscle depletion correlates with disease activity in ulcerative colitis and is reversed after colectomy. Clin Nutr 2017;36:1586-92.

13 Bamba S, Sasaki M, Takaoka A, et al. Sarcopenia is a predictive factor for intestinal resection in admitted patients with Crohn's disease. PLoS One 2017;12:e180036.

14 Møller S, Bendtsen F, Christensen E, et al. Prognostic variables in patients with cirrhosis and oesophageal varices without prior bleeding. J Hepatol 1994;21:940-6.

15 Montano-Loza AJ, Meza-Junco J, Prado CMM, et al. Muscle wasting is associated with mortality in patients with cirrhosis. Clin Gastroenterol Hepatol 2012;10:166-73.

16 Cruz-Jentoft AJ, Bahat G, Bauer J, et al. Sarcopenia: revised European consensus on definition and diagnosis. Age Ageing 2019;48:601-16.

17 Fielding RA, Vellas B, Evans WJ, et al. Sarcopenia: an undiagnosed condition in older adults. current consensus definition: prevalence, etiology, and consequences. International Working group on sarcopenia.. J Am Med Dir Assoc 2011;12:249-56.

18 Chen L-K, Liu L-K, Woo J, et al. Sarcopenia in Asia: consensus report of the Asian Working group for sarcopenia. J Am Med Dir Assoc 2014;15:95-101.

19 Studenski SA, Peters KW, Alley DE, et al. The FNIH sarcopenia project: rationale, study description, conference recommendations, and final estimates. J Gerontol Ser A 2014;69:547-58.

20 Cruz-Jentoft AJ, Landi F, Schneider SM, et al. Prevalence of and interventions for sarcopenia in ageing adults: a systematic review. Report of the International sarcopenia initiative (EWGSOP and IWGS). Age Ageing 2014;43:74859.

21 Cruz-Jentoft AJ, Baeyens JP, Bauer JM, et al. Sarcopenia: European consensus on definition and diagnosis: report of the European Working group on sarcopenia in older people. Age Ageing 2010;39:412-23.

22 Flier JS, Wars O. Obesity wars. Cell 2004;116:337-50.

23 Evans WJ, Morley JE, Argilés J, et al. Cachexia: a new definition. Clin Nutr 2008;27:793-9.

24 Young J. Fit for frailty (summary), 2014.

25 Fried LP, Tangen CM, Walston J, et al. Frailty in older adults: evidence for a phenotype.. J Gerontol A Biol Sci Med Sci 2001;56:M146-57.

26 Sayer AA, Syddall H, Martin H, et al. The developmental origins of sarcopenia. J Nutr Health Aging 2008;12:427-32.

27 Patel HP, Jameson KA, Syddall HE, et al. Developmental influences, muscle morphology, and sarcopenia in communitydwelling older men. The Journals of Gerontology Series A: Biological Sciences and Medical Sciences 2012;67A:82-7.

28 Dodds R, Denison HJ, Ntani G, et al. Birth weight and muscle strength: a systematic review and meta-analysis. J Nutr Health Aging 2012;16:609-15.

29 Roubenoff R. Sarcopenia and its implications for the elderly. Eur J Clin Nutr 2000;54:S40-7.

30 Lexell J, Taylor CC, Sjöström M. What is the cause of the ageing atrophy? total number, size and proportion of different fiber types studied in whole vastus lateralis muscle from 15 - to 83-year-old men. J Neurol Sci 1988;84:275-94.

31 Frontera WR, Hughes VA, Fielding RA, et al. Aging of skeletal muscle: a 12-yr longitudinal study. J Appl Physiol 2000;88:1321-6.

32 Ali S, Garcia JM. Sarcopenia, Cachexia and Aging: Diagnosis, Mechanisms and Therapeutic Options - A Mini-Review. Gerontology 2014;60:294-305.

33 McKee A, Morley JE, Matsumoto AM, et al. Sarcopenia: an endocrine disorder? Endocrine Practice 2017;23:1143-52.

34 Schneider SM, Al-Jaouni R, Filippi J, et al. Sarcopenia is prevalent in patients with Crohn's disease in clinical remission. Inflamm Bowel Dis 2008;14:1562-8.

35 Robinson SM, Reginster JY, Rizzoli R, et al. Does nutrition play a role in the prevention and management of sarcopenia? Clin Nutr 2018;37:1121-32.

36 Russell CA, Elia M. Nutrition screening survey in the UK and Republic of Ireland-A report by the British association for parenteral and enteral nutrition (BAPEN). Bapen 2011:5-7.

37 Zhang T, Cao L, Cao T, et al. Prevalence of Sarcopenia and Its Impact on Postoperative Outcome in Patients with Crohn's Disease Undergoing Bowel Resection. JPEN J Parenter Enteral Nutr 2017;41:592-600.

38 Adams DW, Gurwara S, Silver HJ, et al. Sarcopenia is common in overweight patients with inflammatory bowel disease and may predict need for surgery. Inflamm Bowel Dis 2017;23:1182-6.

39 Pedersen M, Cromwell J, Nau P. Sarcopenia is a predictor of surgical morbidity in inflammatory bowel disease. Inflamm Bowel Dis 2017;23:1867-72.

40 Malmstrom TK, Morley JE. SARC-F: a simple questionnaire to rapidly diagnose sarcopenia. J Am Med Dir Assoc 2013;14:531-2.

41 Cao L, Chen S, Zou C, et al. A pilot study of the SARC-F scale on screening sarcopenia and physical disability in the Chinese older people. J Nutr Health Aging 2014;18:277-83.

42 Woo J, Leung J, Morley JE. Defining sarcopenia in terms of incident adverse outcomes. J Am Med Dir Assoc 2015;16:24752.

43 Yang M, Hu X, Xie L, et al. SARC-F for sarcopenia screening in community-dwelling older adults. Medicine 2018;97:e11726.

44 Ishii S, Tanaka T, Shibasaki K, et al. Development of a simple screening test for sarcopenia in older adults. Geriatr Gerontol Int 2014;14:93-101.

45 Locquet M, Beaudart C, Reginster J-Y, et al. Comparison of the performance of five screening methods for sarcopenia. Clin. Epidemiol 2018;10:71-82.

46 Roberts HC, Denison HJ, Martin HJ, et al. A review of the measurement of grip strength in clinical and epidemiological studies: towards a standardised approach. Age Ageing 2011;40:423-9.

47 Rossi AP, Fantin F, Micciolo R, et al. Identifying sarcopenia in acute care setting patients. J Am Med Dir Assoc 2014;15:303. e7-303.e12.

48 NHS Improvment. Patient safety alert: nasogastric tube misplacement: continuing risk of death and severe harm. Patient Saf Alert 2016.

49 Beaudart $\mathrm{C}, \mathrm{McCloskey} \mathrm{E,} \mathrm{Bruyère} \mathrm{O}$, et al. Sarcopenia in daily practice: assessment and management. BMC Geriatr 2016;16:170.

50 Buckinx F, Landi F, Cesari M, et al. Pitfalls in the measurement of muscle mass: a need for a reference standard. J Cachexia Sarcopenia Muscle 2018;9:269-78.

51 Heymsfield SB, Matthews D. Body composition: research and clinical advances--1993 A.S.P.E.N. research workshop. JPEN J Parenter Enteral Nutr 1994;18:91-103.

52 Shen W, Punyanitya M, Wang Z, et al. Total body skeletal muscle and adipose tissue volumes: estimation from a 
single abdominal cross-sectional image. J Appl Physiol 2004;97:2333-8.

53 Kim EY, Kim YS, Park I, et al. Prognostic significance of CTDetermined sarcopenia in patients with small-cell lung cancer. $J$ Thorac Oncol 2015;10:1795-9.

54 Baracos V, Kazemi-Bajestani SMR. Clinical outcomes related to muscle mass in humans with cancer and catabolic illnesses. Int J Biochem Cell Biol 2013;45:2302-8.

55 Moisey LL, Mourtzakis M, Cotton BA, et al. Skeletal muscle predicts ventilator-free days, ICU-free days, and mortality in elderly ICU patients. Crit Care 2013;17:R206.

56 Perkisas S, Baudry S, Bauer J, et al. Application of ultrasound for muscle assessment in sarcopenia: towards standardized measurements. Eur Geriatr Med 2018;9:739-57.

57 Mulasi U, Kuchnia AJ, Cole AJ, et al. Bioimpedance at the bedside: current applications, limitations, and opportunities. Nutr Clin Pract 2015;30:180-93.

58 Lukaski HC. Evolution of bioimpedance: a circuitous journey from estimation of physiological function to assessment of body composition and a return to clinical research. Eur J Clin Nutr 2013;67:S2-9.

59 Wakimoto P, Block G. Dietary intake, dietary patterns, and changes with age: an epidemiological perspective. J Gerontol A Biol Sci Med Sci 2001;56:65-80.

60 Deer R, Volpi E. Protein requirements in critically ill older adults. Nutrients 2018;10:378-7.

61 NICE Guide. Nutrition support for adults: or nutrition support for adults: oral al nutrition support, enter nutrition support, enteral tube feeding al tube feeding and parenter and parenteral nutrition al nutrition $Y$ your responsibility our responsibility, 2006.

62 Bauer J, Biolo G, Cederholm T, et al. Evidence-Based recommendations for optimal dietary protein intake in older people: a position paper from the PROT-AGE Study Group. $J$ Am Med Dir Assoc 2013;14:542-59.

63 Tieland M, van de Rest O, Dirks ML, et al. Protein supplementation improves physical performance in frail elderly people: a randomized, double-blind, placebo-controlled trial. $J$ Am Med Dir Assoc 2012;13:720-6.

64 Tieland M, Dirks ML, van der Zwaluw N, et al. Protein supplementation increases muscle mass gain during prolonged resistance-type exercise training in frail elderly people: a randomized, double-blind, placebo-controlled trial. J Am Med Dir Assoc 2012;13:713-9.

65 Chalé A, Cloutier GJ, Hau C, et al. Efficacy of whey protein supplementation on resistance exercise-induced changes in lean mass, muscle strength, and physical function in mobility-limited older adults. J Gerontol A Biol Sci Med Sci 2013;68:682-90.

66 Xu Z-rong, Tan Z-ju, Zhang Q, et al. Clinical effectiveness of protein and amino acid supplementation on building muscle mass in elderly people: a meta-analysis. PLoS One 2014;9:e109141.

67 Antonucci A, Fronzoni L, Cogliandro L, et al. Chronic intestinal pseudo-obstruction. World J Gastroenterol 2008;14:2953-61.

68 Oke SM, Rye B, Malietzis G, et al. Survival and CT defined sarcopenia in patients with intestinal failure on home parenteral support. Clin Nutr 2019. doi:10.1016/j. clnu.2019.03.015. [Epub ahead of print: 19 Mar 2019].

69 Konstantakis C, Tselekouni P, Kalafateli M, et al. Vitamin D deficiency in patients with liver cirrhosis. Ann Gastroenterol 2016;29:297-306.

70 Walrand S. Effect of vitamin D on skeletal muscle. Geriatr Psychol Neuropsychiatr Vieil 2016;14:127-34.

71 Borack MS, Volpi E. Efficacy and safety of leucine supplementation in the elderly. J Nutr 2016;146:2625S-9.

72 Kim HK, Suzuki T, Saito K, et al. Effects of exercise and amino acid supplementation on body composition and physical function in community-dwelling elderly Japanese sarcopenic women: a randomized controlled trial. I Am Geriatr Soc 2012;60:16-23.

73 Dillon EL, Sheffield-Moore M, Paddon-Jones D, et al. Amino acid supplementation increases lean body mass, basal muscle protein synthesis, and insulin-like growth factor-I expression in older women. J Clin Endocrinol Metab 2009;94:1630-7.

74 Flakoll P, Sharp R, Baier S, et al. Effect of $\beta$-hydroxy- $\beta$ methylbutyrate, arginine, and lysine supplementation on strength, functionality, body composition, and protein metabolism in elderly women. Nutrition 2004;20:445-51.

75 Vukovich MD, Stubbs NB, Bohlken RM. Body composition in 70 -year-old adults responds to dietary $\beta$-Hydroxy- $\beta$ Methylbutyrate similarly to that of young adults. J Nutr 2001;131:2049-52.

76 Deutz NEP, Pereira SL, Hays NP, et al. Effect of $\beta$-hydroxy- $\beta$ methylbutyrate (HMB) on lean body mass during 10 days of bed rest in older adults. Clin Nutr 2013;32:704-12.

77 Stout JR, Smith-Ryan AE, Fukuda DH, et al. Effect of calcium $\beta$-hydroxy- $\beta$-methylbutyrate (CaHMB) with and without resistance training in men and women $65+$ yrs: a randomized, double-blind pilot trial. Exp Gerontol 2013;48:1303-10.

78 Berghöfer P, Fragkos KC, Baxter JP, et al. Development and validation of the disease-specific short bowel syndrome-quality of life (SBS-QoL ${ }^{\mathrm{TM}}$ ) scale. Clin Nutr 2013;32:789-96.

79 Bunout D, Barrera G, de la Maza P, et al. The impact of nutritional supplementation and resistance training on the health functioning of free-living Chilean elders: results of 18 months of follow-up. J Nutr 2001;131:2441S-6.

80 Suetta C, Andersen JL, Dalgas U, et al. Resistance training induces qualitative changes in muscle morphology, muscle architecture, and muscle function in elderly postoperative patients. J Appl Physiol 2008;105:180-6.

81 Binder EF, Yarasheski KE, Steger-May K, et al. Effects of progressive resistance training on body composition in frail older adults: results of a randomized, controlled trial. $J$ Gerontol A Biol Sci Med Sci 2005;60:1425-31.

82 Brill PA, Probst JC, Greenhouse DL, et al. Clinical feasibility of a free-weight strength-training program for older adults.. J Am Board Fam Pract 1998;11:445-51.

83 Liu CJ, Latham NK. Progressive resistance strength training for improving physical function in older adults. Cochrane Database Syst Rev 2009;3:244-6.

84 Delmonico MJ, Beck DT. The current understanding of sarcopenia: emerging tools and interventional possibilities. Am J Lifestyle Med 2017;11:167-81.

85 Cesari M, Vellas B, Hsu F-C, et al. A physical activity intervention to treat the frailty syndrome in older personsresults from the LIFE-P study. J Gerontol A Biol Sci Med Sci 2015;70:216-22.

86 Westbury LD, Dodds RM, Syddall HE, et al. Associations between objectively measured physical activity, body composition and sarcopenia: findings from the Hertfordshire sarcopenia study (HSs). Calcif Tissue Int 2018;103:237-45.

87 Srinivas-Shankar U, Roberts SA, Connolly MJ, et al. Effects of testosterone on muscle strength, physical function, body composition, and quality of life in intermediate-frail and frail elderly men: a randomized, double-blind, placebo-controlled study. J Clin Endocrinol Metab 2010;95:639-50.

88 Emmelot-Vonk MH, Verhaar HJJ, Nakhai Pour HR, et al. Effect of testosterone supplementation on functional mobility, cognition, and other parameters in older men: a randomized controlled trial. JAMA 2008;299:39-52.

89 Giannoulis MG, Martin FC, Nair KS, et al. Hormone replacement therapy and physical function in healthy older men. Time to talk hormones? Endocr Rev 2012;33:314-77.

90 White HK, Petrie CD, Landschulz W, et al. Effects of an oral growth hormone secretagogue in older adults. J Clin Endocrinol Metab 2009;94:1198-206. 